\title{
Announcing CURRENT CONCEPTS: Exploring What is New, Provocative, and Controversial in Neurocritical Care
}

\author{
Stephan A. Mayer ${ }^{1}$
}

Published online: 18 May 2017

(c) Springer Science+Business Media New York 2017

Neurocritical care is all about pushing boundaries in what is fundamentally one of the last great frontiers of medicine. We have been witness to remarkable advances in the science and technology of brain resuscitation. Mortality from severe brain injury due to stroke and trauma has steadily declined over the past two decades. This is despite the relative paucity of class 1 evidence to support many of the treatments and approaches that we use. Indeed, neurocritical care is a vast and complicated "evidence-free zone."

Adding to the complexity is the fact that new technologies and treatments just keep coming. After 15 years, we are now actually arguing and wondering if therapeutic hypothermia ever really worked-or was it all just a placebo effect created by bias due to unblinding? Staunch adherents of multimodality monitoring are convinced that it is destined to become the next great advance, enabling individualized goal-directed physiological support for the brain-while skeptics view it as a colossal waste of time (at best). We now have the technology to diagnose a previously hidden universe of electrographic seizures and periodic discharges that occupy a new nether world called the "ictal-interictal continuum," and do not have the slightest clue whether suppressing this activity is helpful or harmful.

CURRENT CONCEPTS, a new review series in this journal, is designed to draw these and other fresh areas of question and controversy into sharp focus. This is not the

Stephan A. Mayer

smayer2@hfhs.org

1 William T. Gossett Endowed Chair, Department of Neurology, Neuroscience Institute, Henry Ford Health System, 2799 W Grand Blvd, Detroit, MI 48202, USA place to find the same old definitive review of subarachnoid hemorrhage that we have all seen a hundred times. Our goal is to systematically explore the scientific evidence that supports new practices and management paradigms, or that challenges convention. The series is also focused on topics that cross boundaries with specialties that interface with neurocritical care, including neurosurgery, emergency medicine, radiology, informatics, quality and safety, and healthcare delivery.

Is it safe to treat a complex ruptured aneurysm with a flow diverting stent that diverts flow and pressure, without packing the aneurysmal sac? We are certainly seeing more of this, and this is the topic of the inaugural review in CURRENT CONCEPTS series in this issue [1]. Subsequent articles will explore early mobilization in the ICU, treatment of the ictalinterictal continuum (as promised), ventriculoperitoneal shunt emergencies, and a variety of other topics.

As always, we encourage you to submit your very best work to Neurocritical Care in the form of a submission to the CURRENT CONCEPTS series. Whether it is a new and imaginative treatment approach that you want to explore, a fresh way of thinking about a disease state, or lessons from another subspecialty of medicine that are relevant to the practice of neurocritical care: bring it on. Be part of the collective spirit of creativity and adventure that makes our field so great.

\section{Reference}

1. Walcott BP, Koch MJ, Stapleton CJ, Patel AB Blood flow diversion as a primary treatment method for ruptured brain aneurysms - concerns, controversy, and future directions. Neurocrit Care. 2017. doi:10.1007/s12028-016-0318-y. 